\title{
PENGGUNAAN ALAT PERAGA MANIK - MANIK UNTUK MENINGKATKAN HASIL BELAJAR SISWA KELAS VII SMP NEGERI SOKORIA
}

\author{
Maria Katarina Badhi ${ }^{1}$, Sofia Sa'o ${ }^{2}$, Finsensius Yesekiel Naja ${ }^{3}$ \\ ${ }^{1}$ Program Studi Pendidikan Matematika Universitas Flores, Jln. Sam Ratulangi, Ende -Flores - NTT \\ ${ }^{2}$ Universitas Flores, Jln. Sam Ratulangi, Ende - Flores - NTT \\ ${ }^{3}$ Universitas Flores, Jln. Sam Ratulangi, Ende - Flores -NTT \\ Email: badhirini@gmail.com
}

\begin{abstract}
The purpose of this study is to find out the activities and learning outcomes of students on integer operating materials using beaded props. The type of research used is PTK research. The population used is all students of Grade Vll Grade SMP Sokoria, and the sample in this study was 20 Students of Class Vll SMP Negri Sokoria. The data analysis technique used is a descriptive statistic analysis. Based on activities in cycle I and cycle II, the percentage of students' learning outcomes increased, namely cycle I students who completed only 13 people or with a percentage of $65 \%$ while those who had not completed 7 people or with a percentage of $35 \%$. While in cycle II students completed 20 people or with a percentage of $100 \%$. From cycle I and cycle II, it can be concluded that the percentage of students' learning outcomes increase from 13 complete people to 20, complete people. All students sampled in this study achieved KKM scores.
\end{abstract}

Keywords: integer operation; props; beads

Tujuan dari penelitian ini adalah untuk mengetahui aktivitas dan hasil belajar siswa pada materi operasi bilangan bulat dengan menggunakan alat peraga manik-manik. Jenis penelitian yang digunakan adalah penelitian PTK. Populasi yang digunakan adalah seluruh siswa siswi kelas Kelas Vll SMP Negri Sokoria, dan sampel dalam penelitian ini adalah siswa Kelas Vll SMP Negri Sokoria sebanyak 20 orang. Teknik analisis data yang digunakan adalah analisis statistik deskriptif. Berdasarkan kegiatan pada siklus I dan siklus II, presentase hasil belajar siswa meningkat, yaitu siklus I siswa yang tuntas hanya 13 orang atau dengan presentase $65 \%$ sedangkan yang belum tuntas 7 orang atau dengan presentase $35 \%$. Sedangkan pada siklus II siswa yang tuntas 20 orang atau dengan presentase 100\%. Dari siklus I dan siklus II, dapat disimpulkan bahwa presentase hasil belajar siswa meningkan dari 13 orang yang tuntas, menjadi 20, orang yang tuntas. Semua siswa yang menjadi sampel dalam penelitian ini berhasil mencapai nilai KKM.

Kata kunci: operasi bilangan bulat; alat peraga; manik-manik

\section{PENDAHULUAN}

Matematika adalah bahasa numerik, bahasa symbol, bahasa yang menghilangkan sifat kabur, majemuk dan emosional. Menurut Rahayu, dkk (2014) matematika adalah suatu bidang ilmu pengetahuan dasar yang melatih penalaran supaya berpikir logis dan sistematis dalam menyelesaikan masalah. Matematika merupakan ilmu pengetahuan yang memiliki karakteristik khusus: (1) memiliki objek kajian yang abstrak, (2) bertumpu pada kesepakatan, (3) berpola pikir deduktif, (4) memiliki simbol yang kosong dari arti, (5) memperhatikan semesta pembicaraan, (6) konsisten dalam sistem 
Penggunaan Alat Peraga Manik-Manik Untuk Meningkatkan Kemampuan Siswa Kelas VII SMP Negeri Sokoria

(Subanji, 2013:72). Berdasarkan beberapa pengertian matematika menurut para ahli diatas maka dapat disimpulkan bahwa matematik merupakan suatu bidang ilmu dasar yang melatih pikiran untuk berpikir secara logis.

Menurut pendapat Nana Sudjana (2007:17), Media adalah segala sesuatu yang dapat digunakan untuk menyalurkan pesan dari pengirim ke penerima sehingga dapat merangsang pikiran, perasaan, perhatian, dan minat serta perhatian siswa sedemikian rupa sehingga proses belajar terjadi. Sadiman (2002:6) menyatakan bahwa media pembelajaran adalah bahan, alat, atau teknik yang digunakan dalam kegiatan belajar mengajar dengan maksud agar proses interaksi komunikasi edukasi antara guru dan siswa dapat berlangsung secara tepat guna dan berdaya guna.Dari beberapa penjelasan para ahli diatas, dapat disimpulkan bahwa media pembelajaran

Media dalam prespektif pendidikan merupakan instrumen yang sangat strategis dalam ikut menentukan keberhasilan proses belajar mengajar (Belenky\& Nokes, 2009). Sebab keberadaannya secara langsung dapat memberikan dinamika tersendiri terhadap peserta didik. Kata "media" berasal dari bahasa Latin "medium" yang berarti "perantara" atau "pengantar". Lebih lanjut, media merupakan sarana penyalur pesan atau informasi belajar yang hendak disampaikan oleh sumber pesan kepada sasaran atau penerima pesan tersebut (Cockett\& Kilgour, 2015). Media pembelajaran secara umum adalah alat bantu proses belajar mengajar (Cope, 2015).. Media pembelajaran dipergunakan untuk merangsang pikiran, perasaan, perhatian dan kemampuan atau ketrampilan pembelajaran sehingga dapat mendorong terjadinya proses belajar (Eggen \& Kauchak, 2010). Maka dari beberapa pengertian media diatas dapat disimpulkan bahwa media pembelajaran merupakan alat bantu dalam melaksanakan dan mensukseskan proses belajar mengajar di dalam kelas sehingga ada interaksi aktif antara guru dan siswa.

Menurut Sri Mulyati, (2007), Alat peraga dalam pembelajaran matematika merupakan salah satu komponen dalam proses belajar dan mengajar, alat ini dibuat untuk memvisualisasikan konsepkonsep abstrak yang sedang diajarkan. Penggunaan alat peraga dalam pembelajaran matematika merupakan suatu alternatif meningkatkan daya serap siswa (Fennema \& Romberg, 1999) (Enki, 2014). Fungsi alat peraga adalah sebagai alat untuk menanamkan pengertian yang diajarkan guru kepada siswanya. Sedangkan maksud dan tujuan alat peraga bagi seorang guru adalah memberikan variasi dalam cara-cara mengajar dan memberi lebih banyak realita dalam mengajar sehingga lebih konkrit, lebih bertujuan untuk mencapai maksud (Moyer, 2001) (Ojose\& Sexton, 2009) (Posamentier, Smith \& Stepelman, 2010).

Menurut Erman Suherman (2003:272) peranan alat peraga dalam matematika adalah meletakkan ide-ide dasar yang melandasi sebuah konsep, mengetahui cara membuktikan suatu rumus dan dapat menarik suatu kesimpulan dari data pengamatan. Hal ini sejalan dengan penelitian yang dilakukan oleh L. Suryani dan S.B Seto (2020) bahwa dengan media pembelajaran dapat meningkatkan hasil belajar. Media pembelajaran dalam hal ini dengan menggunakan alat peraga 
Penggunaan Alat Peraga Manik-Manik Untuk Meningkatkan Kemampuan Siswa Kelas VII SMP Negeri Sokoria

manik - manik dapat memudahkan siswa dalam memahami konteks abstrak matematika (Meke, K.D.P., Wutsqa, D.U., \& Alfi, H. D. 2018: 6). Media pembelajaran membuat siswa lebih aktif dan merasa tertarik untuk mengikuti proses pembelajaran sehingga meningkatkan minat belajar, yang berpengaruh signifikan terhadap hasil belajar siswa (Meke, K.D.P, et, al. 2019: 6) (Meke, Wondo \& Wutsqa, 2020: 174).

Media yang menarik salah satunya adalah media manik - manik. Media tersebut sebagai sarana dalam pembelajaran penjumlahan. Pembelajaran menggunakan media manik - manik melalui kegiatan bermain dengan arahan guru. Media tersebut digunakan untuk meningkatkan kemampuan menghitung hasil penjumlahan secara optimal, anak mengetahui konsep penjumlahan, sehingga anak akan termotivasi untuk mengerjakan soal matematika dalam materi penjumlahan (Chariz Fauzy, 2015).

Adapun bentuknya dapat berupa bangun setengah lingkaran yang sisi diameternya digunakan membentuk lingkaran penuh. Bentuk ini bisa dimodifikasi menjadi bentuk lain asal sesuai dengan prinsip kerjanya yang terdiri atas bentuk tanda positif, sedangkan tanda yang lainnya mewakili tanda negatif. seperti membuat gelang dan kalung, setelah menyelesaikan tugas berhitung. Manik-manik adalah alat peraga untuk pembelajaran proses perhitungan bilangan bulat dengan pendekatan menggunakan konsep himpunan. Manik-manik adalah alat peraga ini dapat digunakan untuk memberikan pemahaman tentang pengerjaan bilangan dengan menggunakan pendekatan konsep himpunan.

Berdasarkan uraian pendapat para ahli di atas dapat disimpulkan bahwa alat peraga adalah semua atau segala sesuatu yang dapat digunakan dan dapat dimanfaatkan untuk menjelaskan konsepkonsep pembelajaran dari materi yang bersifat abstrak atau kurang jelas menjadi nyata dan jelas sehingga merangsang pikiran, perasaan, perhatian, serta minat belajar siswa.

\section{METODE}

Jenis Penelitian yang digunakan dalam penelitian ini adalah penelitian tindakan kelas (PTK) dengan pendekatan kuantitatif. Model Mc Taggart (Tampubolon, 2014: 27) menjadi acuan pokok atau dasar dari adanya berbagai penelitian tindakan yang lain, khususnya PTK. Terdiri dari empat komponen, yaitu a) perencanaan (planning), b) tindakan (acting), c) pengamatan (observing) dan refleksi (reflecting). Populasi yang digunakan adalah seluruh siswa siswi kelas Kelas Vll SMP Negri Sokoria, dan sampel dalam penelitian ini adalah siswa Kelas Vll SMP Negri Sokoria sebanyak 20 orang. Teknik analisis data yang digunakan adalah analisis satistik deskriptif.

Dalam penelitian tindakan kelas ini, instrumen penelitian yang akan digunakan yaitu dengan tes hasil belajar siswa. Data hasil belajar siswa ini diperoleh dari siswa dengan menggunakan tes yan`g berbentuk uraian dengan item berjumlah 3. Tes ini bertujuan untuk mengukur sejauh mana peningkatan hasil belajar siswa yang dapat dicapai pada saat proses pembelajaran. Pengolahan data 
Penggunaan Alat Peraga Manik-Manik Untuk Meningkatkan Kemampuan Siswa Kelas VII SMP Negeri Sokoria

Maria Katarina Badhi ${ }^{1}$, Sofia Sa'o ${ }^{2}$, Finsensius Yesekiel Naja ${ }^{3}$

Jupika: Jurnal Pendidikan Matematika, Volume 3. Nomor 2. September 2020. Hal.111-120

dalam penelitian ini dilakukan dengan menggunakan teknik analisis satistik deskriptif. Tujuan dari anlisis ini adalah untuk mendeskripsikan kegiatan siswa selama proses belajar mengajar.

\section{HASIL DAN PEMBAHASAN}

Data nilai pra siklus untuk mengetahui sejauh mana tingkat pemahaman siswa terhadap materi yang di ajarkan ketika menggunakan cara mengajar konvensional, dapat dilihat pada table berikut ini.

Tabel 1. Nilai Pra Sklus

\begin{tabular}{|l|l|}
\hline Data & Perolehan \\
\hline Nilai Maksimal & 88 \\
\hline Rata-rata Nilai & $56,8 \%$ \\
\hline Jumlah Siswa Yang Tuntas & 9 \\
\hline Jumlah nilai yang Tidak Tuntas & 11 \\
\hline Presentase Siswa Tuntas & $45 \%$ \\
\hline Presentase siswa tidak tuntas & $55 \%$ \\
\hline
\end{tabular}

Dari tabel di atas menunjukkan bahwa masih banyak siswa yang nilainya belum mencapai KKM sehingga hasil belajar siswa masih sangat rendah. Hal ini dapat dilihat dari kriteria hasil belajarnya rendah karena 9 orang yang tuntas sesuai KKM yakni $\geq 70$. Berdasarkan permasalahanpermasalahan yang ada, maka peneliti terdorong untuk membangun sebuah sistem pembelajaran altenatif dengan sebuah model pembelajaran Alat peraga dengan tujuan untuk membuat siswa lebih kreatif dan semangat dalam proses pembelajaran.

Data hasil tes pra tindakan ini juga dapat dilihat pada grafik berikut:

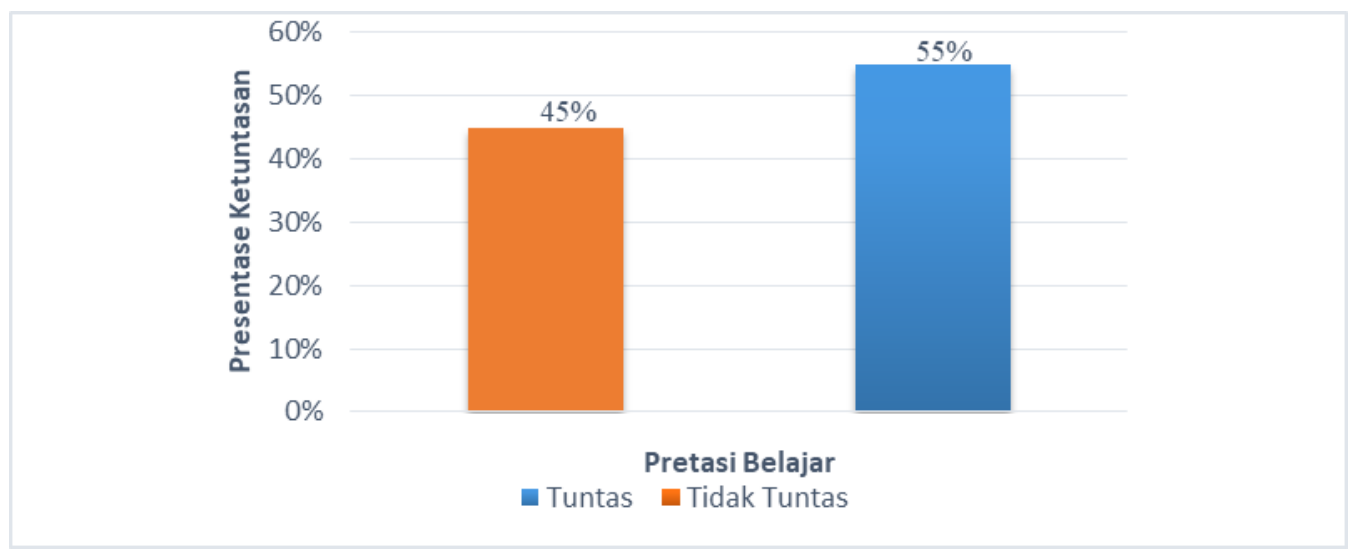

\section{Gambar 1 Diagram Nilai Ketuntasan Pra Siklus}

Berdasarkan permasalahan-permasalahan yang ada, maka peneliti terdorong untuk membangun sebuah sistem pembelajaran altenatif dengan sebuah model pembelajaran Alat peraga dengan tujuan untuk membuat siswa lebih kreatif dan semangat dalam proses pembelajaran. Berdasarkan hasil observasi di kelas, peneliti menemukan beberapa hal yang menjadi penyebab rendahnya hasil belajar siswa, yakni: Suasana kelas yang cenderung gaduh yang menyebabkan siswa tidak memperhatikan penjelasan guru Siswa kurang aktif dan jenuh dalam pembelajaran. 
Berdasarkan temuan-temuan di atas, maka peneliti memberi gambaran dan solusi untuk mengatasi kesulitan siswa kelas VII dengan menerapkan model pembelajaran Alat peraga dalam pembelajaran matematika khususnya materi bilangan pecahan. Proses pembelajaran ini akan dilakukan dalam Penelitian Tindakan Kelas (PTK) dengan tujuan untuk meningkatkan hasil belajar siswa.

Tabel 2. Nilai Siklus I

\begin{tabular}{|l|l|}
\hline Data & Perolehan \\
\hline Nilai Maksimal & 90 \\
\hline Rata-rata Nilai & $\mathbf{7 4 , 0 5 \%}$ \\
\hline Jumlah Siswa Yang Tuntas & 13 \\
\hline Jumlah nilai yang Tidak Tuntas & 7 \\
\hline Presentase Siswa Tuntas & $65 \%$ \\
\hline Presentase siswa tidak tuntas & $35 \%$ \\
\hline
\end{tabular}

Berdasarkan hasil belajar siswa pada tabel diatas dengan pembelajaran Alat peraga materi bilangan pecahan pada siswa kelas VII dapat dijelaskan bahwa rata-rata hasil belajar siswa mencapai 74,05. Maka berdasarkan tabel di atas bahwa peserta didik yang tuntas hanya 13 orang atau dengan presentase ketuntasan mencapai 65\%. Hasil tersebut menunjukkan bahwa siklus I secara klasikal masuk kategori belum tuntas belajarnya, karena ketuntasan yang dicapai hanya $65 \%$ jauh dari yang diharapkan pada yaitu $\geq 80 \%$. Hal ini dikarenakan siswa masih canggung dan guru masih menggunakan kalimat yang membuat siswa bingung.

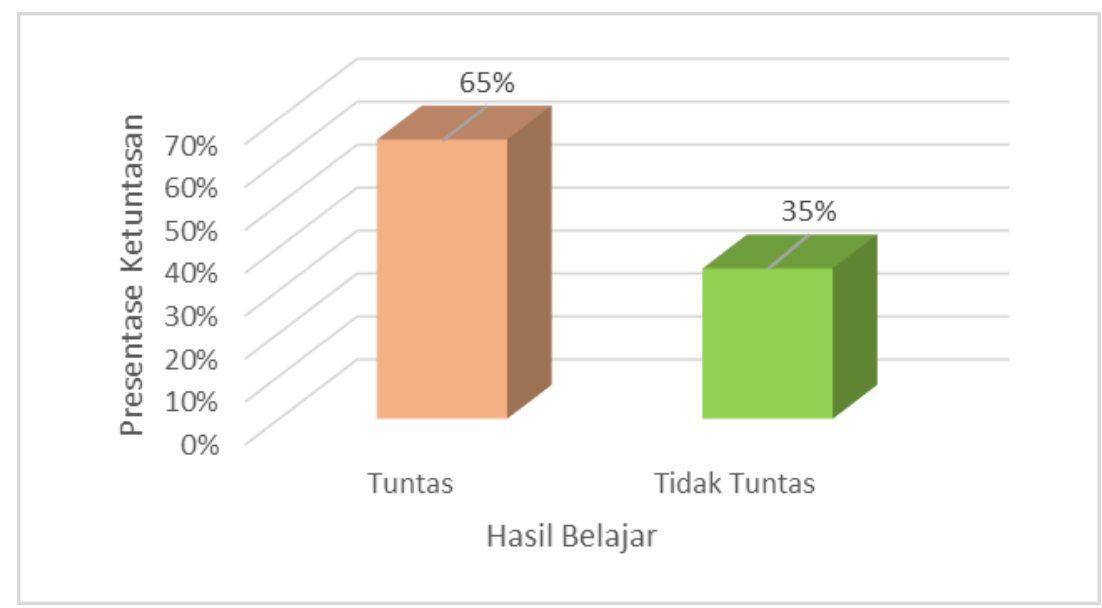

\section{Gambar 2 Grafik Ketuntasan Belajar Siklus I}

Berdasarkan hasil belajar siswa pada tabel diatas dengan penerapan pembelajaran Alat peraga materi bilangan pecahan pada siswa kelas VII dapat dijelaskan bahwa rata-rata hasil belajar siswa 
Penggunaan Alat Peraga Manik-Manik Untuk Meningkatkan Kemampuan Siswa Kelas VII SMP Negeri Sokoria

mencapai 78,45. KKM materi bilangan 71, maka berdasarkan tabel di atas bahwa peserta siswa yang tuntas hanya 13 orang atau dengan presentase ketuntasan mencapai $65 \%$ sedangkan yang belum tuntas 7 orang dengan presentase 35\%. Hasil tersebut menunjukkan bahwa siklus I secara klasikal masuk kategori belum tuntas belajarnya, karena ketuntasan yang dicapai siswa secara klasikal hanya $65 \%$ jauh dari yang diharapkan pada SKM yaitu $\leq 80 \%$. Hal ini dikarenakan siswa masih canggung dan guru masih menggunakan kalimat yang membuat siswa bingung.

Hasil observasi aktivitas belajar siswa dalam kegiatan pembelajaran siklus I dengan penerapan model pembelajaran Alat peraga. Hasil yang diperoleh adalah jumlah skor 32 dan presentase keaktifan siswa 53,3\% atau dengan kriteria penilaian kurang baik.

Ada beberapa hal yang perlu diperbaiki dari kegiatan siklus I antara lain dilihat dari sisi guru, dalam hal ini guru adalah peneliti perlu menguasai lagi langkah-langkah pembelajaran Alat peraga. Selanjutnya dari sisi siswa, peneliti menghimbau agar lebih aktif dalam kegiatan diskusi kelompok sehingga nilai KKM bisa meningkat. Dilihat dari sisi waktu, dalam hal ini waktu pembelajaran tidak terlalu banyak, sehingga kesempatan untuk siswa bertanya tidak ada. Jadi demi meningkatkan hasil belajar matematika yang optimal, guru dalam hal ini peneliti memutuskan untuk melanjutkan penelitian ke siklus berikutnya yaitu siklus II.

Tabel 2. Nilai Siklus II

\begin{tabular}{|l|l|}
\hline Data & Perolehan \\
\hline Nilai Maksimal & 100 \\
\hline Rata-rata Nilai & $86,65 \%$ \\
\hline Jumlah Siswa Yang Tuntas & 20 \\
\hline Jumlah nilai yang Tidak Tuntas & 0 \\
\hline Presentase Siswa Tuntas & $100 \%$ \\
\hline Presentase siswa tidak tuntas & $0 \%$ \\
\hline
\end{tabular}

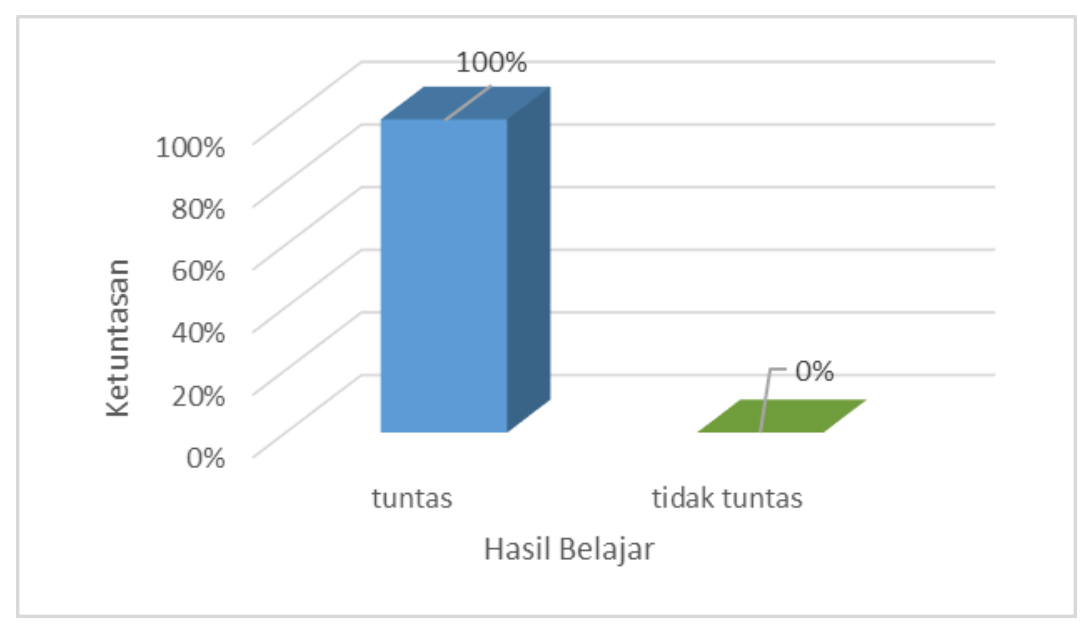


Penggunaan Alat Peraga Manik-Manik Untuk Meningkatkan Kemampuan Siswa Kelas VII SMP Negeri Sokoria

Maria Katarina Badhi ${ }^{1}$, Sofia Sa'o ${ }^{2}$, Finsensius Yesekiel Naja ${ }^{3}$

Jupika: Jurnal Pendidikan Matematika, Volume 3. Nomor 2. September 2020. Hal.111-120

\section{Gambar 3 Grafik Ketuntasan Belajar Siklus II}

Dari tabel dan grafik diatas dapat disimpulkan Berdasarkan hasil belajar siswa pada tabel diatas dengan meningkatkan pembelajaran Alat peraga materi bilangan pecahan pada siswa kelas VII dapat dijelaskan bahwa rata-rata hasil belajar siswa mencapai KKM materi bilangan pecahan 70, maka berdasarkan tabel di atas bahwa 20 orang yang mengikuti tes presentase ketuntasan mencapai $100 \%$ atau 20 siswa tersebut semua tuntas sedangkan yang belum tuntas tidak ada atau 0\%. Hasil tersebut menunjukan bahwa siklus 11 secara klasikal masuk kategori tuntas belajarnya, karena ketuntasan yang dicapai siswa secara klasikal 100\% atau meningkat jauh dari pada $\mathrm{kKM} \leq 85 \%$.

Hasil observasi aktivitas belajar siswa dalam kegiatan pembelajaran siklus II dengan penerapan model pembelajaran jigsaw. Hasil yang diperoleh adalah jumlah skor 57 dan presentase keaktifan siswa 95\% atau dengan kriteria penilaian sangat baik. Dari pernyataan tersebut dapat disimpulkan bahwa terjadi peningkatan jika dibandingkan dengan siklus 1 . Hal ini menunjukkan bahwa jumlah siswa yang memiliki pemahaman pembelajaran matematika materi Bilanagan pecahan sangat baik.

\section{Tahap Refleksi Siklus II}

Setelah pelaksanaan siklus II selesai, peneliti bersama observer melakukan refleksi terhadap pembelajaran siklus II. Berdasarkan data yang diperoleh dari hasil observasi, catatan lapangan, dan hasil tes kemampuan penguasaan materi peserta siswa selama tindakan pembelajaran siklus I, peneliti bersama observer mengadakan diskusi untuk mengetahui hal-hal yang harus dipertahankan, ditingkatkan, atau ditinggalkan. Dari diskusi tersebut dapat disimpulkan bahwa proses tindakan siklus II mengalami peningkatan yang signifikan, artinya segi peroses tindakan siklus II berhasil.

Terbukti bahwa penggunaan model pembelajaran Alat peraga untuk materibilangan pecahan sudah mampu memancing hasil belajar peserta didik dalam pembelajaran matematika. Pada akhir tindakan, kedua hasil refleksi sebagai berikut: pembelajaran terkesan sangat menyenangkan, semua siswa rata-rata sudah aktif dalam pembelajaran, aktivitas belajar siswa semakin meningkat walaupun waktunya tidak cukup atau tidak banyak yang disediakan, hasil belajar siswa mengalami peningkatan disetiap siklus.

Penggunaan alat peraga manik-manik dalam proses pembelajaran matematika dimaksudkan agar siswa mampu menemukan solusi permasalahan matematika. Dalam pelaksanaannya penggunaan alat peraga manik manik dalam prosesnya mampu meningkatkan hasil belajar matematika. Hasil ini sejalan dengan penelitian yang dilakukan oleh Meke, et. al, (2018) yang menyatakan bahwa dalam pelaksanaannya, penggunaan media pembelajaran mampu membantu siswa untuk mengkonkretkan konsep matematika yang terasa abstrak dalam pembelajaran. Alat peraga manik manik sebagai media pembelajaran juga membantu siswa dalam memahami proses berhitung, sehingga siswa lebih tertarik dan aktif dalam mengcari solusi permasalahan dalam matematika. Hal ini sejalan dengan hasil penelitian Seko (2020) dalam hasil penelitiannya juga menyimpulkan bahwa 
Penggunaan Alat Peraga Manik-Manik Untuk Meningkatkan Kemampuan Siswa Kelas VII SMP Negeri Sokoria

Jupika: Jurnal Pendidikan Matematika, Volume 3. Nomor 2. September 2020. Hal.111-120

penggunaan alat peraga mampu meningkatkan hasil belajar siswa karena minat siswa dalam prosesnya membuat siswa aktif untuk menemukan solusi dalam permasalahan matematika yang diberikan. Hal ini berarti bahwa penggunaan alat peraga manik-manik mampu membuat siswa tertarik sehingga minat siswa dalam pembelajaran (Meke, dkk., 2020)

\section{KESIMPULAN}

Berdasarkan kegiatan pada siklus I dan siklus II, presentase hasil belajar siswa meningkat, yaitu siklus I siswa yang tuntas hanya 13 orang atau dengan presentase $65 \%$ sedangkan yang belum tuntas 7 orang atau dengan presentase $35 \%$. Sedangkan pada siklus II siswa yang tuntas 20 orang atau dengan presentase $100 \%$. Dari siklus I dan siklus II, dapat disimpulkan bahwa presentase hasil belajar siswa meningkan dari 13 orang yang tuntas, menjadi 20, orang yang tuntas. Semua siswa yang menjadi sampel dalam penelitian ini berhasil mencapai nilai KKM. Pembelajaran dengan menggunakan alat peraga pada mata pelajaran matematika materi bilangan bulat dapat meningkat hasil belajar yang lebih baik, dan lebih aktif.

\section{DAFTAR PUSTAKA}

Aguswedi. 2011. “makalah media pembelajaran”. Tersedia pada: http://belajarpsikologi.com/penger tian-media-pembelajaran.

Belenky, D. M. \& Nokes, T. J. (2009). Examining the Role of Manipulatives and Metacognition on Engagement, Learning, and Transfer. The Journal of Problem Solving. 2(2), 102-129.

Cockett, A. \& Kilgour, P. W. (2015) "Mathematical Manipulatives: Creating an Environment for Understanding, Efficiency, Engagement, and Enjoyment," Teach Collection of Christian Education. 11(5). Available at: http://research.avondale.edu.au/teachcollection/vol1/iss1/5

Cope, L. (2015). Math manipulatives: making the abstract tangible. Delta Journal of Education. 5(1), 10-19

Cahry Fauzy. 2015. Peningkatan Hasil Belajar Matematika Melalui Penggunaan Media Manik manik pada Siswa Tunagrahita Ringan Kelas VII SLB PGRI Badas Kabupaten Kediri. Jurnal Ortopedagogia. 1(4) 336-342

Eggen, P., \& Kauchak, D. (2010). Educational psychology: Windows On Classrooms.8th ed. Upper Saddle River, New Jersey: Merrill Pearson

Enki, K. (2014). Effects of using manipulatives on seventh grade students' achievement in transformation geometry and orthogonal views of geometric figures. Unpublished master's thesis. Ankara: Middle East Technical University.

Fennema, E., \& Romberg, T. A. (Eds). (1999). Mathematics classrooms that promote understanding. New Jersey: Lawrence Erlbaum Associates, Inc. 
Penggunaan Alat Peraga Manik-Manik Untuk Meningkatkan Kemampuan Siswa Kelas VII SMP Negeri Sokoria

Meke, K.D.P., Wutsqa, D.U., \& Alfi, H. D. (2018). The Effectiveness of Problem-based Learning Using Manipulative Materials Approach on Cognitive Ability in Mathematics Learning. J. Phys.: Conf. 1097 (012135) 1 - 7

Meke, K.D.P, et, al. (2019). Problem based learning usingmanipulative materials to improve student interest of mathematics learning. J. Phys.: Conf. Ser. 1157 (032099),1-8.

Meke, K.D.P., Wutsqa, D.U., \& Wondo, M. T. S. (2020). Pembelajaran Problem Based Learning dengan Penggunaan Bahan Manipulatif Ditinjau Dari Minat Belajar Matematika. Jurnal Penelitian Pembelajaran Matematika. 13 (2), p. 164-177

Moyer, P. S. (2001). Are we having fun yet? How teachers use manipulatives to teach mathematics. Educational Studies in Mathematics. 47(2), 175-197.

Ojose, B. \& Sexton, L. (2009). The effect of manipulative materials on mathematics achievement of first grade students. The Mathematics Educator. 12(1), 3-14

Posamentier, A. S., Smith B. S., \& Stepelman J. (2010). Teaching secondary mathematics: teaching and enrichment unit. (8th ed). Boston, MA: Allyn \& Bacon.

Rahayu, dkk.(2014). Eksperimentasi Model Pembelajaran Kooperatif Tipe TAI Dan NHT Pada Pokok Bahasaan Relasi dan Fungsi Ditinjau Dari Adversity Quotient(AQ) Siswa KelasVIII SMP Negeri Pringsewu. Jurnal Elektronik pembelajaran matematika Vol 2, No 3, ISSN 2339-1685.

Sadiman dkk (2006). Media Pendidikan. Jakarta :PT Raja Grafindo Persada,

Seko, W. M. M. D. S. (2020). Penerapan media pembelajaran etnomatematika gomo toma "congklak untuk materi operasi bilangan bulat pada siswa kelas VII SMPK Alvares Paga Tahun Pelajaran 2018/2019. Scientifical Colloquiel: Jurnal PEndidikan Matematika Universitas Flores. 3(1), 7 15

Subanji. (2013). Pembelajaran Matematika KreatifdanInovatif. Malang: Universitas Negeri Malang (UM Press).

Sudjana Nana , dkk, (2007). Teknologoi Pengajaran. Bandung: Sinar baru Algensindo,

Suryani, L., \& Seto, S. B. (2020). Penerapan Media Audio Visual untuk Meningkatan Perilaku Cinta Lingkungan pada Golden Age. Jurnal Obsesi: Jurnal Pendidikan Anak Usia Dini, 5(1), 900-908.

Sri Mulyati, 2007. Usaha Meningkatkan Hasil Belajar dan Aktivitas Belajar Siswa Kelas I Semester II Tahun Ajaran 2006/2007 Pokok Bahasan Menggunakan Nilai Tempat dalam Penjumlahan dan Pengurangan dengan Metode Demonstrasi dan Memanfaatkan Alat Peraga Manik-manik di Sekolah Dasar Perumnas Banyumanik 14 Kecamatan Banyumanik Kota Semarang. Universitas Negeri Semarang 
Penggunaan Alat Peraga Manik-Manik Untuk Meningkatkan Kemampuan Siswa Kelas VII SMP Negeri Sokoria

Maria Katarina Badhi ${ }^{1}$, Sofia Sa'o ${ }^{2}$, Finsensius Yesekiel Naja ${ }^{3}$

Jupika: Jurnal Pendidikan Matematika, Volume 3. Nomor 2. September 2020. Hal.111-120

Suherman, Eman, dkk. 2003. Strategi Pembelajaran Matematika Kontemporer edisi revisi). Bandung: UPI

Tampubolon, Saur.(2014). Penelitian Tindakan Kelas Sebagai Pengembangan Profesi Pendidik dan Keilmuan. Jakarta: Penerbit Erlangga. 